\title{
Clinical, biochemical, and genetic analysis of a Chinese Han pedigree with holocarboxylase synthetase deficiency: a case report
}

Zhenzhu Zheng ${ }^{1}$, Gaopin Yuan ${ }^{1}$, Minyan Zheng ${ }^{1}$, Yiming Lin ${ }^{1}$, Faming Zheng ${ }^{1}$, Mengyi Jiang ${ }^{2}$, Lin Zhu $^{2 *}$ and Qingliu Fu ${ }^{1 *}$ (D)

\begin{abstract}
Background: Holocarboxylase synthetase (HLCS) deficiency is a rare inborn disorder of biotin metabolism, which results in defects in several biotin-dependent carboxylases and presents with metabolic ketoacidosis and skin lesions.

Case presentation: In this paper, we report a Chinese Han pedigree with HLCS deficiency diagnosed by using next-generation sequencing and validated with Sanger sequencing of the HLCS and BTD genes. The Chinese proband carries the common missense mutation c.1522C > T (p.Arg508Trp) in exon 9 of the HLCS gene, which generates an increased $K_{m}$ value for biotin. A novel frameshift mutation c.1006_1007delGA (p.Glu336Thrfs*15) in exon 6 of the HLCS gene is predicted to be deleterious through PROVEAN and MutationTaster. A novel heterozygous mutation, c.638_642delAACAC (p.His213Profs*4), in the BTD gene is also identified.

Conclusions: The Chinese proband carries the reported Arg508Trp variant, the novel 2-bp frameshift mutation c.1006_1007delGA (p.Glu336Thrfs*15), which expands the mutational spectrum of the HLCS gene, and the novel heterozygous mutation c.638_642delAACAC (p.His213Profs*4), which expands the mutational spectrum of the BTD gene. Furthermore, reversible hearing damage is rarely reported in patients with HLCS deficiency, which deserves further discussion.
\end{abstract}

Keywords: HLCS deficiency, Case report, Arg508Trp, Frameshift mutation, Hearing damage

\section{Background}

Multiple carboxylase deficiency (MCD), a rare autosomal recessive disorder, is divided into two types depending on the pattern of enzyme deficiency: holocarboxylase synthetase deficiency (HLCS deficiency, OMIM \#253270) and biotinidase deficiency (BTD, OMIM \#253260). HLCS (EC 6.3.4.10) is an enzyme that

\footnotetext{
*Correspondence: zhulin@biosan.cn; zhyetyy@163.com

${ }^{2}$ Genuine Diagnostics Company Limited, 859 Shixiang West Road, Hangzhou 310007, Zhejiang Province, China

${ }^{1}$ Neonatal disease screening center, Quanzhou Children's Hospital, 700

Fengze Street, Quanzhou 362000, Fujian Province, China
}

catalyzes the biotinylation of four biotin-dependent carboxylases; these are pyruvate carboxylase (EC 6.4.1.1), acetyl-CoA carboxylase (EC 6.4.1.2), propionyl-CoA carboxylase (EC 6.4.1.3), and methylcrotonyl-CoA carboxylase (EC 6.4.1.4) [1, 2]. The HLCS gene is located on chromosome 21q22.1; pathogenic variants at this location produce severe metabolic decompensation [3]. Clinically, patients with HLCS deficiency usually present with poor feeding, respiratory distress, lethargy, vomiting, hypotonia, seizures, developmental delay, alopecia, and skin rash [4-7].

C C The Author(s). 2020 Open Access This article is licensed under a Creative Commons Attribution 4.0 International License, which permits use, sharing, adaptation, distribution and reproduction in any medium or format, as long as you give appropriate credit to the original author(s) and the source, provide a link to the Creative Commons licence, and indicate if changes were made. The images or other third party material in this article are included in the article's Creative Commons licence, unless indicated otherwise in a credit line to the material. If material is not included in the article's Creative Commons licence and your intended use is not permitted by statutory regulation or exceeds the permitted use, you will need to obtain permission directly from the copyright holder. To view a copy of this licence, visit http://creativecommons.org/licenses/by/4.0/ The Creative Commons Public Domain Dedication waiver (http://creativecommons.org/publicdomain/zero/1.0/) applies to the data made available in this article, unless otherwise stated in a credit line to the data. 
The mutation spectrum of the HLCS gene correlates with the clinical phenotypes, and molecular genetic analysis is helpful for definitive diagnosis [8]. An increasing number of novel pathogenic variants have been reported recently. For example, Donti et al. have revealed five cases of HLCS deficiency with broad differences in initial presentation and phenotype, and they have also described six novel pathogenic variants: c.500A $>C$ (p.Tyr167Ser), c.1532A $>$ T (p.Asn511Ile), c.2078G >C (p.Gly693Ala), c.977G > A (p.Gly326Glu), c.1710C > G (p.Asn570Lys), and c.1519 + 5G > A [9]. In addition, Quinonez et al. have identified the novel heterozygous variant c.996G >C (p.Gln332His) and a paracentric inversion on chromosome 21 by utilizing cytogenetic analysis [10]. In this study, we investigated a Chinese Han pedigree with HLCS deficiency and described the relationship between molecular mutation and clinical manifestation. Additionally, this HLCS deficiency patient presented the unusual clinical symptom of hearing damage during the acute episode.

\section{Case presentation \\ Subjects}

The proband was a one-year-old male patient. His nonconsanguineous parents and his elder sister were also included in this study. The patient underwent thorough physical examinations and other tests, including blood gas analysis, blood ammonia testing, plasma acylcarnitine profiling, urinary organic acid analysis, brainstem auditory evoked potential (BAEP) studies, and genetic testing. His family only underwent physical examination and genetic testing. The filter-paper dried blood spot sample was pretreated with a NeoBase Non-derivatized MS/MS Kit (PerkinElmer Life and Analytical Sciences, Turku, Finland), and the acylcarnitine profile was analyzed by using liquid chromatography-tandem mass spectrometry (Acquity TQD, Waters, Milford, MA, USA). The urinary organic acids were analyzed by using gas chromatography-tandem mass spectrometry (7890B/5977A, Agilent Technologies, Santa Clara, CA, USA). Blood gas analysis was performed with an automated blood gas analyzer (Cobas B221, Roche Diagnostics GmbH, Mannheim, Germany). The BAEP was recorded by using a KeyPoint electromyogram device (Dantec Medical A/S, Skovlunde, Denmark). Written informed consent for data collection and publication was obtained from the parents. This study was approved by the Ethical Committee, Quanzhou Children's Hospital of Fujian. The study was prepared in accordance with the Health Insurance Portability and Accountability Act (HIPAA) regulations.

\section{Clinical presentation}

The proband, a Chinese Han boy, was first brought to the dermatology department at the age of 1 year with a skin rash around the periorbital and perioral areas; he was treated for eczema. Three weeks later, he was referred directly to the pediatric intensive care unit with serious tachypnea, moaning, and heart failure. The rash had expanded to the limbs, neck, and groin. Capillary blood gas analysis showed metabolic acidosis with $\mathrm{pH}$ 6.98 , a base excess of $-26 \mathrm{mmol} / \mathrm{L}$, bicarbonate level of $3.9 \mathrm{mmol} / \mathrm{L}$, anion gap of $25.2 \mathrm{mmol} / \mathrm{L}$, elevated lactate of $13.1 \mathrm{mmol} / \mathrm{L}$ (normal $<2 \mathrm{mmol} / \mathrm{L}$ ), and elevated ammonia of $152.0 \mu \mathrm{mol} / \mathrm{L}$ (normal $<47 \mu \mathrm{mol} / \mathrm{L}$ ). Biochemical laboratory results on the day of admission showed low ornithine $(15.99 \mu \mathrm{mol} / \mathrm{L}$; normal $42-325 \mu \mathrm{mol} / \mathrm{L})$ and a plasma acylcarnitine profile with low free carnitine and large increases in $\mathrm{C} 5-\mathrm{OH}, \mathrm{C} 5-\mathrm{OH} / \mathrm{CO}, \mathrm{C} 5-\mathrm{OH} / \mathrm{C} 8$, $\mathrm{C} 3 / \mathrm{C} 2$, and $\mathrm{C} 3 / \mathrm{C} 0$. The urinary organic acid profile displayed excessive excretion of 3-hydroxyisovaleric acid, acetylglycine, propionylglycine, 3-methylcrotonylglycine, methylcrotonylglycine, 3-hydroxybutyric acid, pyruvic acid, and lactic acid. Increases in the amounts of 2-keto-3methyl-pentanoic acid and 2-keto-isocaproic acid suggested a metabolic disorder of the branched-chain amino acids. Based on the characteristic plasma acylcarnitine profile and urinary excretion pattern, the patient was presumptively diagnosed with MCD and treated immediately with biotin ( $20 \mathrm{mg}$ bid). The skin rash was eliminated and the normal acid-base balance was restored 5 days later. Subsequently, the level of $\mathrm{C} 5-\mathrm{OH}$ decreased gradually and the urinary organic acid profile showed undetectable acetylglycine, propionylglycine, 3-methylcrotonylglycine, and methylcrotonylglycine (Table 1).

During the acute episode, a BAEP study showed that the wave I latency and I-V interpeak latency intervals were all significantly prolonged. Additionally, the bilateral thresholds also increased: the left to $50 \mathrm{dbnhl}$ and the right to $60 \mathrm{dbnhl}$. These results indicated that the patient's bilateral hearing was impaired. The hearing impairment was predicted to be sensorineural. A cattle encephalon glycoside and ignotin injection was immediately administered. After biotin therapy for 43 days, the results of a repeat BAEP study showed that the bilateral thresholds had both decreased to $30 \mathrm{dbnhl}$, which indicated that the hearing damage had been reversed (see Fig. S1).

\section{DNA sequencing analysis}

Peripheral whole blood or dried blood spot samples were collected from the proband and his family members. Genomic DNA was extracted by using Qiagen Blood DNA Mini Kits (Qiagen, Hilden, Germany) according to the manufacturer's instructions and was stored at $80^{\circ} \mathrm{C}$ until further use. All exons and adjacent noncoding regions of abnormal $\mathrm{C} 5-\mathrm{OH}$-related genes were amplified by polymerase chain reaction (PCR) and subsequently screened via next-generation sequencing 
Table 1 Metabolites in plasma and urine

\begin{tabular}{|c|c|c|c|c|c|}
\hline & $\begin{array}{l}13 \text { months } \\
\text { measurement }\end{array}$ & $\begin{array}{l}15 \text { months } \\
\text { measurement }\end{array}$ & $\begin{array}{l}17 \text { months } \\
\text { measurement }\end{array}$ & $\begin{array}{l}24 \text { months } \\
\text { measurement }\end{array}$ & Ref. range \\
\hline \multicolumn{6}{|l|}{ Acylcarnitine in plasma } \\
\hline $\mathrm{C} 5 \mathrm{OH}(\mu \mathrm{mol} / \mathrm{L})$ & 3.88 & 1.66 & 0.53 & 0.37 & $0.07-0.5$ \\
\hline $\mathrm{CO}(\mu \mathrm{mol} / \mathrm{L})$ & 4.86 & 30.25 & 26.87 & 26.43 & $9.5-50$ \\
\hline $\mathrm{C} 2(\mu \mathrm{mol} / \mathrm{L})$ & 7.99 & 9.87 & 11.88 & 10.27 & $3.4-45$ \\
\hline C3 $(\mu \mathrm{mol} / \mathrm{L})$ & 4.35 & 0.62 & 1.13 & 1.3 & $0.2-4.5$ \\
\hline $\mathrm{C} 5 \mathrm{OH} / \mathrm{CO}$ & 0.80 & 0.055 & 0.02 & 0.01 & $0-0.02$ \\
\hline $\mathrm{C} 5 \mathrm{OH} / \mathrm{C} 8$ & 77.6 & 33.2 & 17.67 & 7.4 & $1.22-18$ \\
\hline $\mathrm{C} 3 / \mathrm{C} 2$ & 0.54 & 0.063 & 0.095 & 0.13 & $0.01-0.2$ \\
\hline $\mathrm{C} 3 / \mathrm{CO}$ & 0.90 & 0.02 & 0.042 & 0.05 & $0.01-0.2$ \\
\hline \multicolumn{6}{|l|}{ Organic acids in urine } \\
\hline 3-methylcrotonylglycine ( $\mu \mathrm{mol} / \mathrm{mmol}$ creatinine) & 24.70 & 0.00 & - & 0.00 & 0 \\
\hline 3-hydroxyisovaleric acid ( $\mu \mathrm{mol} / \mathrm{mmol}$ creatinine) & 3.63 & 3.00 & - & 1.46 & $0-2.3$ \\
\hline methylcrotonylglycine $(\mu \mathrm{mol} / \mathrm{mmol}$ creatinine) & 17.51 & 0.00 & - & 0.00 & 0 \\
\hline $\begin{array}{c}\text { acetylglycine } \\
\text { ( } \mu \mathrm{mol} / \mathrm{mmol} \text { creatinine) }\end{array}$ & 6.13 & 0.00 & - & 0.00 & $0-0.1$ \\
\hline propionylglycine ( $\mu \mathrm{mol} / \mathrm{mmol}$ creatinine) & 36.71 & 0.00 & - & 0.00 & 0 \\
\hline $\begin{array}{l}\text { lactic acid } \\
(\mu \mathrm{mol} / \mathrm{mmol} \text { creatinine })\end{array}$ & 247.95 & 4.23 & - & 4.81 & $0-4.7$ \\
\hline $\begin{array}{l}\text { pyruvic acid } \\
\text { ( } \mathrm{mol} / \mathrm{mmol} \text { creatinine) }\end{array}$ & 58.14 & 6.45 & - & 3.42 & $0-24.1$ \\
\hline 3-hydroxybutyric acid ( $\mu \mathrm{mol} / \mathrm{mmol}$ creatinine) & 966.37 & 2.52 & - & 0.00 & $0-3.7$ \\
\hline 2-keto-3-methyl pentanoic acid ( $\mu \mathrm{mol} / \mathrm{mmol}$ creatinine) & 6.16 & 0.00 & - & 0.00 & 0 \\
\hline 2-keto-isocaproic acid ( $\mu \mathrm{mol} / \mathrm{mmol}$ creatinine) & 6.16 & 0.00 & - & 0.00 & 0 \\
\hline
\end{tabular}

(NGS) with a NextSeq 500/550 Buffer Cartridge v2 Sequencing Kit on a high-throughput sequencing instrument (Nextseq 500, Illumina Inc., San Diego, CA, USA). Sequence analyses were performed by using BWA, GATK, Annovar, etc.

Identified variants HLCS c.1522C > T, c.1006 1007delGA and BTD c.638_642delAACAC were validated by Sanger sequencing of samples from all family members. The HLCS exon 9 and exon 6 sequences were amplified by PCR using the following primers, respectively: forward 1, 5' -CTCACAGAAGCAGAACATTAT-3' and reverse 1 , 5'-GAAAACTCCGAGAGCACT-3'; forward 2, 5'TGTAAAACGACGGCCAGTTAGTGCTATCTTTCCC CTTC-3' and reverse $2,5^{\prime}$-CAGGAAACAGCTATGACC GATGATTTCCAAACCCG-3'. BTD exon 4 was amplified with the following primers: forward $3,5^{\prime}$-TGTAAA ACGACGGCCAGTTTTAGTTGAGATGGGGTTT-3' and reverse 3, 5'-CAGGAAACAGCTATGACCCTCC AGAGGGGTGTGTAT-3'. Sanger sequencing was performed with an ABI Prism 3500 Genetic Analyzer (Applied Biosystems, Foster City, CA, USA), and the results were analyzed with DNASTAR software (http://www. dnastar.com/).
Genetic sequencing results reveal that the patient carries the maternal missense mutation c.1522C $>\mathrm{T}$ (p.Arg508Trp) in exon 9 of the HLCS gene, the novel paternal 2-bp deletion c. 1006_1007delGA (p.Glu336Thrfs"15) in exon 6 of the HLCS gene, and also the novel paternal 5-bp deletion c.638_642delAACAC (p.His213Profs*4) in exon 4 of the BTD gene (Fig. 1e). Furthermore, his family's genotypes have been confirmed at a heterozygous level by Sanger sequencing (Fig. 1b and c), and his healthy elder sister has been shown to carry the same mutations as his father (Fig. 1d). The pedigree is shown in Fig. 1a. The p.Arg508Trp mutation has been widely reported to be pathogenic $[11,12]$. The p.Glu336Thrfs"15 and p.His213Profs"4 mutations could not be found in the literature or the 1000 Genome, ESP6500, ExAC, or dbSNP databases and were not detected in 100 healthy individuals. The effect of these mutations on protein function is predicted to be deleterious by PROVEAN and MutationTaster (Table 2). Additionally, the p.Glu336Thrfs"15 mutation resides in a conserved stretch of amino acids (Fig. 2a) and leads to truncated proteins lacking the conserved domains of HLCS (Fig. 2b). When all this information is taken into account, the 


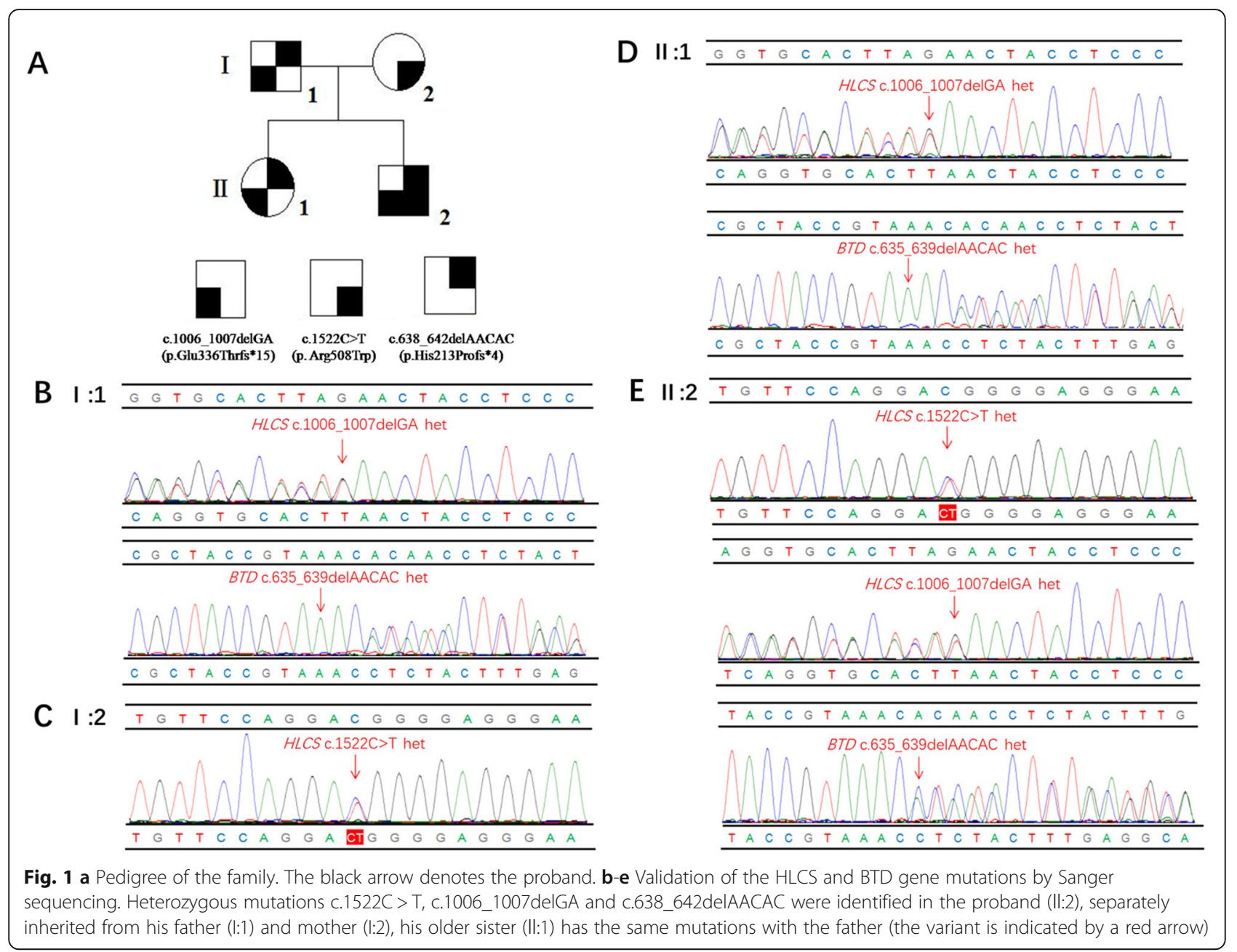

c.1006_1007delGA (p.Glu336Thrfs*15) mutation is considered to be deleterious and likely pathogenic.

\section{Discussion and conclusions}

The HLCS protein possesses three structural domains: two in the $\mathrm{C}$-terminal region and one in the $\mathrm{N}$-terminal half $[13,14]$. It has previously been reported that most of the HLCS mutations producing increased $K_{\mathrm{m}}$ values for biotin are located in the $\mathrm{C}$-terminal catalytic region [14]. Additionally, those mutations in the $\mathrm{N}$-terminal region are located outside the catalytic domain and reduce the $V_{\max }$ of the HLCS enzyme [11].

Table 2 Gene mutations in the proband with HLCS deficiency

\begin{tabular}{|c|c|c|c|}
\hline Gene & $H L C S^{A}$ & $H L C S^{A}$ & $B T D^{B}$ \\
\hline Exon & 9 & 6 & 4 \\
\hline Nucleotide change & c. $1522 C>T$ & c.1006_1007delGA & c.638_642delACAAC \\
\hline Amino acid change & p.Arg508Trp & p.Glu336Thrfs*15 & p.His213Profs*4 \\
\hline Parental origin & Maternal & Paternal & Paternal \\
\hline Type of change & Het & Het & Het \\
\hline PROVEAN/MutationTaster prediction (score) & Deleterious(-6.559)/ Disease causing(0.99) & $\begin{array}{l}\text { Deleterious(-4.224)/ } \\
\text { Disease causing(1.0) }\end{array}$ & $\begin{array}{l}\text { Deleterious }(-3.927) \\
\text { Disease causing (1.0) }\end{array}$ \\
\hline EXAC MAF (Allele Count) & $\begin{array}{l}0.00003302 \\
(4 / 121122)\end{array}$ & NA & NA \\
\hline Comment & Pathogenic & Novel & Novel \\
\hline References & Dupuis (1996) Hum Mol Genet 5, 1011 [13] & This study & This study \\
\hline
\end{tabular}


A

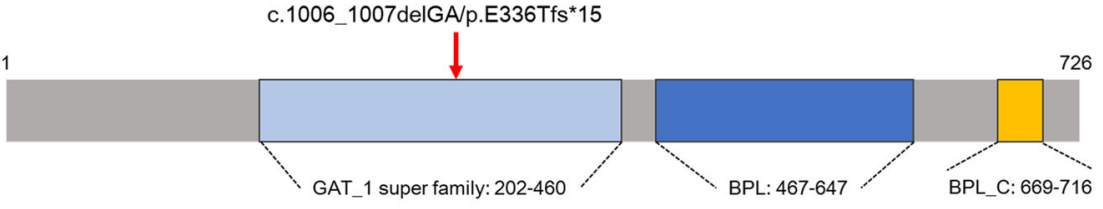

B

\begin{tabular}{|c|c|}
\hline Proban & GEAVLCQVHLIT'T SQLQHSANSRRF * \\
\hline Human & GEAVLCQVHLIELPPSSN I VQTPEDFNLLKSSNFRR \\
\hline Pan & GEAVLCQVHLIELPPSSN I VQTPEDFNLLKSSNFRR \\
\hline Gorilla & ELLPPS I I VQTPEDFNLLKSSNFRR \\
\hline Rhinopithecus & ELPPSSD I VQAPEDFNLLKSSNFRR \\
\hline Callithrix & GEAVLCQVHLILILPSSD IVQTPEDFNLLKSSNFRR \\
\hline Cercocebus & GEAVLCQVHLIELPPSSD I VQTPEDFNLLKSSNFRR \\
\hline Orcinus & GEA VLCQVHLLILPPSSPV VQTQEDFNLLKSSNFRR \\
\hline Galeopterus & EILPPSVMVQTE EDFNLLKSSN I RR \\
\hline Nannospalax & GEAVLCQVHLLLPPSSP IVQTQ EDFNLLKSSNMRR \\
\hline
\end{tabular}

Fig. 2 a Domains structure of HLCS protein. The novel frameshift mutation identified in the proband is indicated by a red arrow. $\mathbf{b}$ Conserved amino acid sequences of HLCS (amino acid 336, highlighted by a red box) and the predicted truncated HLCS caused by the frameshift mutation (c.1006_1007delGA) identified in this proband

As mentioned above, this Chinese boy carries a heterozygous c.1522C > T (p.Arg508Trp) mutation and a novel frameshift c.1006_1007delGA (p.Glu336Thrfs*15) mutation. The Arg508Trp mutation is located in the Cterminal region and generates an elevated $K_{\mathrm{m}}$ value. Patients bearing $K_{\mathrm{m}}$ mutants present the late-onset form of the deficiency and respond well to biotin therapy $[15,16]$. Clinically, this patient became symptomatic at the age of 11 months, which corresponds with the late-onset form. Moreover, the novel frameshift mutation c.1006_ 1007delGA has been identified. This is predicted to induce an amino acid substitution of glutamate with threonine at position 336 (p.Glu336Thr). After position 336, a termination codon is formed at the fifteenth amino acid, which is predicted by PROVEAN and MutationTaster to be deleterious. The novel Glu336Thr mutation is speculated to be located outside the biotin-binding region, and the related kinetic changes require further experimental testing. However, as a result of the biotin-responsive allele (Arg508Trp), our patient can be predicted to be responsive to biotin administration [17]; the clinical outcome supports this deduction.

The BAEP study showed that the patient's bilateral hearing had been slightly impaired. Patients with HLCS deficiency presenting abnormal BAEPs have rarely been reported, and the reason is worthy of discussion. Slavin et al. reported a girl with HLCS deficiency presenting conductive hearing loss as a result of cerumen impaction [7], but this is different from the situation with our patient. Additionally, our patient's hearing impairment recovered after 43 days of biotin therapy, which is different from the irreversible hearing loss of biotinidase deficiency. Hence, we speculate that the hearing impairment may be secondary to the primary disorder of HLCS deficiency. However, this is just a hypothesis because there is no literature or experimental data. In any case, there are almost no reports that patients with HLCS deficiency present hearing impairment, so we believe that this case is noteworthy and the cause of the impairment needs to be confirmed.

In conclusion, we report a Chinese Han boy who shows clinical features and biochemical parameters that are consistent with the genetic data and who clearly presents HLCS deficiency. He carries a common Arg508Trp variant, which corresponds with the biotin-responsive and late-onset presentation. The novel 2-bp frameshift mutation c.1006_1007delGA (p.Glu336Thr) would expand the mutational spectrum of the HLCS gene. Moreover, there is a rare association of bilateral hearing damage with HLCS deficiency in this patient. However, this occurrence needs to be investigated further.

\section{Supplementary information}

Supplementary information accompanies this paper at https://doi.org/10. 1186/s12881-020-01080-4.

Additional file 1: Figure S1. A The BAEP study during an acute episode in the patient. (B) The BAEP study after biotin therapy for 43 days.

\section{Abbreviations}

MCD: Multiple carboxylase deficiency; HLCS: Holocarboxylase synthetase; BTD: Biotinidase deficiency; BAEP: Brainstem auditory evoked potential; 
HIPAA: Health Insurance Portability and Accountability Act; PCR: Polymerase chain reaction; NGS: Next-generation sequencing

\section{Acknowledgements}

The authors would like to thank the patient's family for their cooperation.

\section{Authors' contributions}

ZZ designed the study and performed the experimental work. GY and MZ collected and analyzed the clinical data. YL and FZ followed the patient, collected the biochemical parameters, analyzed the biochemical results, and designed the figures. MJ and LZ performed the mutation analysis. ZZ and LZ wrote the first draft of the manuscript. QF guided the whole research process and revised the manuscript carefully. All authors read and approved the final manuscript.

\section{Funding}

This study was supported by the Quanzhou Science and Technology Plan Project in China (No. 2019N049S). The funds were used to acquire the data of gene analysis. The authors declare no interests or conflicts.

\section{Availability of data and materials}

The reference sequence for validation of the Arg508Trp and Glu336Thrfs*15 variants in the HLCS gene was acquired from the NCBI Nucleotide database by using accession number NM_000411.6. The reference sequence for validation of the His213Profs 4 variant in the BTD gene was acquired from the NCBI Nucleotide database by using accession number NM_000060.2. The raw sequencing data is available in the NCBI's Sequence Read Archive (SRA) [with accession number: SRR11965409 (https://dataview.ncbi.nlm.nih.gov/ object/SRR11965409)].

\section{Ethics approval and consent to participate}

This study has been approved by the Ethical Committee, Quanzhou Children's Hospital of Fujian. Written informed consent to participate was obtained from the respective parents of the patient, his elder sister, and the 100 healthy individuals (younger than the age of 16); the parents agreed themselves and their children taking part in this study.

\section{Consent for publication}

Written informed consent was obtained from the respective parents of the patient, his elder sister, and the 100 healthy individuals (under the age of 18) for the publication of their own and their children's genetic data, clinical details, and any accompanying images.

\section{Competing interests}

The authors declare no conflicts of interest.

Received: 1 February 2020 Accepted: 28 June 2020

Published online: 29 July 2020

\section{References}

1. He L, Hamm JA, Reddy A, Sams D, Peliciari-Garcia RA, Mcginnis GR, et al. Biotinylation: a novel posttranslational modification linking cell autonomous circadian clocks with metabolism. Am J Physiol-Heart C. 2016;310(11): H1520-32.

2. Saunders ME, Sherwood WG, Duthie M, Surh L, Gravel RA. Evidence for a defect of holocarboxylase synthetase activity in cultured lymphoblasts from a patient with biotin-responsive multiple carboxylase deficiency. Am J Hum Genet. 1982;34(4):590.

3. Tammachote R, Janklat S, Tongkobpetch S, Suphapeetiporn K, Shotelersuk V. Holocarboxylase synthetase deficiency: novel clinical and molecular findings. Clin Genet. 2010;78(1):88-93.

4. Bandaralage SPS, Farnaghi S, Dulhunty JM, Kothari A. Antenatal and postnatal radiologic diagnosis of holocarboxylase synthetase deficiency: a systematic review. Pediatr Radiol. 2016;46(3):357-64.

5. Malvagia S, Morrone A, Pasquini E, Funghini S, Donati MA. First prenatal molecular diagnosis in a family with holocarboxylase synthetase deficiency. Prenatal Diag. 2005;25(12):1117-9.

6. Sakamoto O, Suzuki Y, Li X, Aoki Y, Hiratsuka M, Holme E, et al. Diagnosis and molecular analysis of an atypical case of holocarboxylase synthetase deficiency. Eur J Pediatr. 2000;159(1-2):18-22.
7. Slavin TP, Zaidi SJ, Neal C, Nishikawa B, Seaver LH. Clinical presentation and positive outcome of two siblings with holocarboxylase synthetase deficiency caused by a homozygous L216R mutation. JIMD Rep. 2013;12: 109-14.

8. Tang NLS, Hui J, Yong CKK, Wong LTK, Applegarth DA, Vallance HD, et al. A genomic approach to mutation analysis of holocarboxylase synthetase gene in three chinese patients with late-onset holocarboxylase synthetase deficiency. Clin Biochem. 2003;36(2):145-9.

9. Donti TR, Blackburn PR, Atwal PS. Holocarboxylase synthetase deficiency pre and post newborn screening. Mol Genet Metab Rep. 2016;7:40-4.

10. Quinonez SC, Seeley AH, Lam C, Glover TW, Barshop BA, Keegan CE. Paracentric inversion of chromosome 21 leading to disruption of the HLCS gene in a family with holocarboxylase synthetase deficiency. JIMD Rep. 2016;34:55-61.

11. Suzuki $Y$, Yang $X$, Aoki $Y$, Kure $S$, Matsubara $Y$. Mutations in the holocarboxylase synthetase gene HLCS. Hum Mutat. 2005;26(4):285-90.

12. Yang X, Aoki Y, Li X, Sakamoto O, Hiratsuka M, Kure S, et al. Structure of human holocarboxylase synthetase gene and mutation spectrum of holocarboxylase synthetase deficiency. Hum Genet. 2001;109(5):526-34.

13. Campeau E, Gravel RA. Expression in escherichia coli of $\mathrm{N}$ - and C-terminally deleted human holocarboxylase synthetase. Influence of the N-terminus on biotinylation and identification of a minimum functional protein. J Biol Chem. 2001;276(15):12310-6.

14. Pendini NR, Bailey LM, Booker GW, Wilce MC, Wallace JC, Polyak SW Microbial biotin protein ligases aid in understanding holocarboxylase synthetase deficiency. BBA-Proteins Proteom. 2008;1784(7-8):973-82.

15. Bailey LM, Ivanov RA, Jitrapakdee S, Wilson CJ, Wallace JC, Polyak SW. Reduced half-life of holocarboxylase synthetase from patients with severe multiple carboxylase deficiency. Hum Mutat. 2008;29(6):47-57.

16. Zempleni J, Mock DM. Bioavailability of biotin given orally to humans in pharmacologic doses. Am J Clin Nutr. 1999;69(3):504-8.

17. Hui J, Law E, Chung C, Fung S, Yuen P, Tang N. The first reported HLCS gene mutation causing holocarboxylase synthetase deficiency in a Vietnamese patient. World J Pediatr. 2012;8(3):278-80.

\section{Publisher's Note}

Springer Nature remains neutral with regard to jurisdictional claims in published maps and institutional affiliations.

\section{Ready to submit your research? Choose BMC and benefit from:}

- fast, convenient online submission

- thorough peer review by experienced researchers in your field

- rapid publication on acceptance

- support for research data, including large and complex data types

- gold Open Access which fosters wider collaboration and increased citations

- maximum visibility for your research: over $100 \mathrm{M}$ website views per year

At BMC, research is always in progress.

Learn more biomedcentral.com/submissions 